\title{
ENRICHING VIEWS OF INFORMATION SYSTEMS WITHIN ORGANIZATIONS: A FIELD THEORY
}

\author{
Shaila Miranda and Robert Zmud \\ Division of MIS, Michael F. Price College of Business, University of Oklahoma, USA
}

\begin{abstract}
Three perspectives have dominated research on IT adoption, implementation, use, and impacts: technological determinism, organizational imperatives, and the emergent perspective. While the last is most realistic in its assumptions, it falls short in two respects. First, structuration theory, which has served as the underpinning for most research based on this perspective, while acknowledging the potentially constraining effects of structure, presumes that all agency is equally unconstrained within a set of structures. Given this presumption, a second shortfall of the emergent perspective is that it fails to shed light on the systematic manner in which agency is constrained.

In this paper, we first consider the advantages of field theory in augmenting our current understanding of IT in organizations. We then identify three specific organizational fields that may be useful in modeling the disparate constraints on entities' agency vis-à-vis IT. The first is the production field, which encompasses organizations' core or primary business processes. The second is the coordination field, comprised of organizations' activities at the interface of various core activities as well as supportive activities and internal relationship management, The third is the field of co-opetition, i.e., the arena of organizations' management of its relationships with external entities.
\end{abstract}

Keywords: IT Theory, Field Theory

\section{INTRODUCTION}

The last 40 years have seen dramatic changes in the manner and extent to which information systems (IS) are applied within organizations, and in the focus and the depth of scholarly research examining management, design, 
and use of IS within organizations. In practice, IS have moved from technologies used for the sporadic automation of discrete tasks, with minimal influence on organizational performance, to technologies that are embedded deeply within and broadly across organizations. In scholarship, IS research has moved from a science framed through relatively simple, static models and a positivistic epistemology to a science that applies increasingly complex, dynamic models and epistemological diversity. Success in domains of both practice and research is dependent on the availability of models that capture the richness of IS phenomena, their application within organizations (also organizational constellations), and their evolutionary paths within organizations.

The objective of this paper is to develop a field theory of IS that portrays and enables analyses of capabilities, values, agency, and evolution of IS within organizations. This should facilitate more robust explanations of both organizational stability and transformation, as well as the differential agency of actors within the organizational fields in which IS are embedded.

\section{DEFINITIONS OF TECHNOLOGY AND OF IS}

A key challenge involves achieving clarity and consensus around the meaning of the central object of study, in our case of IS. However, the concept of technology, alone, is elusive:

- Technology "is oriented ...to the problem, given the end, of choosing the appropriate means" (Weber, 1978, p. 67).

- It is a "collection of plant, machines, tools and recipes ... for the execution of the production task and the rationale underlying their utilization" (Woodward, 1994/1965, p. 4).

- It is "systematic knowledge transformed into, or made manifest by, tools" (Tornatzky \& Fleischer, 1990, p.9).

- Technology is the product of one-dimensional (non-reflexive) understanding. It "becomes mastered only when from the first and without reservation 'yes' is said unconditionally to it. This means that the practical mastering of technology in its unconditional unfolding already presupposes the metaphysical submission to technology" (Heidegger, 1941, as cited in Zimmerman, 1990, p. 89).

A common theme across the first three definitions is that technologies are tools built from knowledge held by organizational actors to accomplish desired ends. IS are distinguished from other types of technology in that the nature of their work involves transmission, processing, and framing of data, information, and knowledge. As with other technologies, IS are not neutral in these processes, but rather embody capabilities, i.e., actionable 
knowledge, and values as do human agents. Such capabilities and values are activated and manifested only in the relationships between IS agents and human agents. Thus, IS assume a reality only in their relationships with other agents within organizational fields. In this perspective of IS, we are consistent with Heidegger's view of technology - in his view the problem of constrained consciousness derives not from modern technologies themselves, but rather from the manner in which we relate to them (Zimmerman, 1990). Our perspective differs from prevailing perspectives not in our definition of IS, but in our view of the agency of IS and of that of human actors in relation to IS.

In the MIS literature, IS are defined in terms of their 'structural features', i.e., "the specific rules and resources, or capabilities, offered by the system" and their spirit, i.e., the "normative frame with regard to behaviors that are appropriate in the context of the technology" (DeSanctis and Poole, 1994, p. 126). An IS, then, represents a functionality bundle that reflects the intentions of its builders, yet is appropriable toward users' intentions, even when objectives of builder and user collide. An IS thus is "both engine and barrier for change; both customizable and rigid; both inside and outside organizational practices. It is product and process." (Star and Ruhleder, 1996, p. 111).

More recent structurational perspectives take exception with such a view, suggesting that IS structures emerge via practice, rather than being embedded a priori within IS or within organizations (Orlikowski, 2000). Such an amendment, while consistent with Heidegger's focus on our relationships with technology as being its defining characteristic, falls short of locating rules and resources within the relationships among technological and human agents. Furthermore, it fails to explicitly recognize that some organizational actors have more freedom in their relationships with technology than do others (e.g., Lamb and King, 2003). This is a key difference between structuration and a theoretical perspective representative of field theory (as developed here), which posits that constraints that operate upon agents and their freedom to enact structures is a function of their position within a given field.

In summary, we argue that existing conceptualizations of organizational IS evince three weaknesses. First, they fail to account for interdependencies across organizational IS. Second, they fail to adequately account for the evolution of an IS. Third, they fail to account for the complex sets of relationships that exist among a focal IS, other implemented IS, members of the organization, and the organization itself. In their focus on the IS 'artifact', existing conceptualizations tend to privilege the technical over the social, even though the boundary between "technical" (i.e., social artifacts) and "social" (i.e., an organization and its human actors) is a control-oriented 
social-construction (Bloomfield and Vurdubakis, 1994). These limitations can be overcome through developing the notion of organizational fields in conceptualizing the IS role within organizations.

\section{TOWARD A THEORY OF IS WITHIN ORGANIZATIONAL FIELDS}

Field theory represents a median ground between structuration theory's arena of unconstrained agency and critical theory's arena of completely constrained agency, focusing instead on constraints that arise as a function of agents' positions within a given field. In developing this field theoretic perspective on organizational information systems, we rely primarily on theoretical articulations of fields by Bourdieu, derived from sociological studies of fields such as academics, sports, and aesthetics (e.g., Bourdieu, 1984) and augmented by subsequent research on fields such as gastronomy (Ferguson, 1998). We temper this sociological perspective on field theory with the notions of the field developed by Lewin in his psychological work based on individuals and groups (e.g., de Rivera, 1976) and that of DiMaggio and Powell (1983) on organizational fields. Field theory accounts for changes without causal or triggering agents: instead, location within the field evokes change in an element, which has "particular attributes that make them susceptible to field effects" (Martin, 2003, p. 4). In other words, the impetus for change and constrictions on agency are a function of an agent's position in a field. Field theories are both similar to and different from mechanistic theories, which utilize lower-level, intermediate constructs to explain a phenomenon, and functionalist theories, which rely on explanations of instrumentality. Like mechanistic theories, but unlike functionalist theories, they focus on local action; like functionalist theories but unlike mechanistic theories, they look for global patterns that explain local action (Martin, 2003).

A field is a "configuration of objective relations between positions. These positions are objectively defined, in their existence and in the determinations they impose upon their occupants, agents or institutions, by their present and potential situation in the structure" (Bourdieu and Wacquant, 1992, p. 97). Here, the 'structure' being referenced is based on and reproduces distributions of power and capital, creating relations of domination and subordination as well as homology (equivalence). These distributions of power and capital relate to the gradients of field forces that differentially impinge on the actants within the field. The structure of a field is "self-regulating, self-validating, and self-perpetuating" (Ferguson, 1998, p. 598). A field translates "external economic or political phenomena into 
its own terms for its own use or, rather, for the use of its occupants" (Ferguson, 1998, p. 597). In other words, the forces within an organizational field are oriented toward the perpetuation of the field, not toward the survival or prosperity of the individual agents that constitute it. Field theory highlights the fact that actants' behaviors are not simply triggered by environmental stimuli, but rather that the effects of stimuli on actants' responses is mitigated by field forces such as habit, habitus, and group behavior (Bourdieu, 1984; Lewin, 1951).

While in Bourdieu's view sociological field forces are an objective reality, in Lewin's (1951) perspective, psychological forces derive from agents' subjective experiences, rather than from objective, physical phenomena. These perspectives on field forces are not contradictory. Rather, psycho-social field forces are the objectification of actants' collective subjective experiences over time, culminating from their individual enactments of those experiences. These enactments constitute actants' "life spaces", i.e., socio-psychological fields that are products of actants' states, history, and context (Lewin, 1951).

Fields are constituted by distinct sets of values or forces and capabilities. The values within sociological fields are the forces that define the field. An important facet of the field is the capital available to each agent, as capital makes games not a matter of mere chance but rather of historicallyaccumulated capability (Bourdieu, 1983). Value forces are inextricably linked to the distribution of capital within the field, differentially subjugating actants based on their accumulated capital. Recognition of capital is therefore imperative if we are not to view organizational fields as locations of "instantaneous mechanical equilibria between agents who are treated as interchangeable particles" (Bourdieu, 1983, p. 241).

A distinct form of capital underlies every field (Bourdieu, 1983). A sufficient amount of that capital is a condition of membership in the field (Bourdieu and Wacquant, 1992). Capital acquires meaning within a field only by virtue of the values ascribed to it by actants. For example, artistic ability holds little value in fields of economic endeavor, and would therefore convey little position power (Bourdieu, 1983). Position in a field, or relative power, is then a function of actors' accumulated capital relative to that of others and the values subscribed to within the field.

Capital and values represent dualities that are constitutive of fields. Within the context of a defined set of values, capital "confers a power over the field, over the materialized or embodied instruments of production or reproduction whose distribution constitutes the very structure of the field, and over the regularities and the rules which define the ordinary functioning of the field, and thereby over the profits engendered in it" (Bourdieu and Wacquant, 1992, 101). In other words, competencies and prescriptive rules 
provide the basis for agreement and the resolution of disputes within different fields (Boltanski and Thevenot, 1987). In the context of organizational fields, the capital that human actors have is their portfolio of capabilities, i.e., actionable knowledge (Churchman, 1971). "To be capable of some thing is to have a generally reliable capacity to bring that thing about as a result of intended action" (Dosi, Nelson, and Winter, 2002, p. 2). Thus, a defining characteristic of an organizational field is its capability requirements.

The connotation of "power" in field theory is not about agents' ability to directly constrain each other's actions; rather, it "refers to a "possibility of inducing forces' of a certain magnitude on another" (Lewin, 1951, p. 40). Thus, agents' power is enabled by and exercised only indirectly through field forces. The distribution of capabilities in organizational fields coincides with the distribution of power. "There is a distinction between the execution of high-frequency, repetitive daily business by low-level employees and the decisions of executives about the development and deployment of capabilities" (Dosi et al., 2002). Position in organizational fields thus accrues from one's capability to create rather than to simply execute the creations of others. Note that 'capability' is used in the dual sense of competence as well as freedom to perform. While fields require and permit certain capabilities in their actants, the presence of certain actants may attenuate or heighten the salience of others' capabilities. When actants are deficient in capability-based capital, they may trade based on an alternate form of capital, e.g., time. Consider, for example, specialists deficient in the typing skills required by a new IT: "Specialists improvised ways of dealing with backlogged data entry... working after hours to get caught up" (Orlikowski, 1996, p. 73).

Underlying the notion of the field is recognition that "external factors economic crises, technological change, political revolutions, or simply the demand of a given group - exercise an effect only through transformations in the structure of the field where these factors obtain. The field refracts" (Bourdieu, 1988, p. 544). The asymmetric perception of a threat or an opportunity, based on actants' positions within the field, creates disequilibrium. Differential perception of threat or opportunity within a field yields disparate efforts by actants to develop capabilities to address the threat or leverage the opportunity. Differences in actants' capabilities may subsequently transform the field as new capabilities and/or value systems become salient. Alternatively, actants may collectively ignore external factors, thereby inducing stagnation.

Thus, a field is "also a field of struggles (Bourdieu and Wacquant, 1992, p. 101). 'Struggle' implies both the production of continuity and the production of change. Underlying struggles may be human intentionality: 
"Acts of intention occur when the subject's needs lead him to foresee a situation in which he desires to act in a certain way, but knows that the situation will not automatically bring about the desired action. When successful, the subject's act of intention functions to transform the future psychological field" (de Rivera, 1976, p. 46). However, the idea of struggles in the field is not inconsistent with Orlikowski's (1996) notion of organizational transformation being wrought through "ongoing improvisation enacted by organizational actors trying to make sense of and act coherently in the world". Rather, we view such sensemaking as inherently a struggle, entailing dissonance and conflict that culminates in revised action and cognition (Weick, 1995). Nor does the term 'struggle' always entail strategy: "There is a production of difference which is in no way the product of a search for difference" (Bourdieu and Wacquant, 1992, p. 100, italics in original). Yet, these struggles too often yield transformations of the field (Bourdieu and Wacquant, 1992).

Strategic actions at play within a field are neither unconstrained nor equally constrained for all actants (Bourdieu and Wacquant, 1992). The ability to withstand pressures or susceptibility to those pressures is a direct function of human agents' position in the field. The boundary of the field is established by the marginalization of field forces. The field terminates at a point where its forces cease to constrain agency. While bounded, fields do not operate autonomously. Rather, interdependencies exist among fields, e.g., within literary and political fields (Bourdieu, 1988). These interdependencies develop through actants' simultaneous participation in multiple fields and are necessary for alignment (Garvin, 1995). However, the consequent referencing of multiple logics of action yields problems in resolving disagreements (Boltanski and Thevenot, 1987). Field interdependencies also play out in the "structural subordination" of one field to another (Bourdieu, 1988, p. 546). Such subordination operates differently on actants, based on their respective positions in each of the fields. Positions are not simply inherited, but are also the product of actants' strategic efforts at differentiation and subsequent field transformations. Such differentiation enables actants to configure unique niches within the field so as to minimize their competition with other actants and, perhaps, even provide them with a monopoly regarding their niche. (Bourdieu and Wacquant, 1992, Bourdieu, 1988).

Field theory thus allows for simultaneous accounts of structure and history, reproduction and transformation, and statics and dynamics (Bourdieu and Wacquant, 1992, p. 90). In fact, field theory requires that we integrate these analytical dichotomies: "We cannot grasp the dynamics of a field if not by a synchronic analysis of its structure and, simultaneously, we cannot grasp this structure without a historical, that is, genetic analysis of its 
constitution and of the tensions that exist between positions in it, as well as between this field and other fields" (Bourdieu and Wacquant, 1992, p. 91).

In sum, the salient contributions of field theory to our reconceptualization of organizational IS are the following. First, we view both technological artifacts and human actors as agents occupying different positions in a field. Fields constitute and are constituted by capital and value forces, and agents' positions are a function of their accumulated capital that is afforded prominence based on the values of the field. Position constrains agency differently making access to capital and deviations from established routines more difficult for some agents than for others. Through intentional agency and the intended and unintended consequences of that agency, agents' positions in fields shift. Whereas unintended consequences are treated as a matter of chance in structuration theory, they are viewed as a function of field dynamics in field theory.

What is the role of IS within such organizational fields? Consistent with actor network theory, we attribute agency to societal artifacts, specifically to IS (Law and Hassard, 1999). As agents within an organizational field, IS possess capital as do human agents. However, the capital possessed by IS appears in an objectified form in contrast to the embodied capital of human actors (Bourdieu, 1983). Embodied capital, i.e., "long-lasting dispositions of the mind and body" (Bourdieu, 1983, p. 243), or "habitus" (Bourdieu, 1988, p. 546) are a product of one's historical environment. Objectified capital also known as structural capital - is owned by the organization, while embodied capital - the property of human actors - may simply be rented by the organization (Stewart, 1999).

As an actor with capital, an IS can be both instrumental in redistributing capability-based capital within a field, e.g., downgrading experts' capabilitybased capital and upgrading that of novices (Orlikowski, 1993). It may alter human actants' positions in a field by spotlighting the location of such capital, e.g., call center databases provide a "brag record" for specialists with "more calls in there than anybody else" (Orlikowski, 1996, p. 77). In substituting requirements of technical capabilities for domain capabilities, IT may erode domain capabilities in an organization, e.g., attrition of domain knowledge following implementation of a community knowledge system for biologists (Star and Ruhleder, 1996). Similarly, changes in capability requirements may engender resistance, and consequently, transformation of the field (Gill, 1996; Markus and Pfeffer, 1983). 


\section{FIELDS OF ORGANIZATIONAL PRACTICE}

Fields are instantiated through practice or routines: "The field is a critical mediation between the practices of those who partake of it and the surrounding social and economic conditions" (Bourdieu and Wacquant, 1992, p. 105). Practices or routines are characterized by repetition, by recognizable patterns of action, by multiple participants, and by interdependent actions. They have ostensive and performative aspects, i.e., the idea versus the enactment, and there is a recursive relationship between ostensive and performative. The ostensive can guide enactments, serving "as a template for behavior or a normative goal" (Feldman and Pentland, 2003, p. 106). It provides a basis for accounting or justifying enactments, and supplies a label that is useful in communicating about what is being done. The performative maintains, but can also modify and create the ostensive (Feldman and Pentland, 2003). Modifications may or may not be legitimized and incorporated into the ostensive (e.g., the performance of virtual visits in the ostensible practice of recruiting). When they are, modifications to the cognitions underlying the field or new cognitions emerge: "When substantive actions are taken, words come to life and become meaningful" (Feldman and Pentland, 2003, p. 108).

Thus, in performance, routines get improvised, subsequently modifying underlying cognitions. In the reification of routines via IS, though, reflexivity is eliminated, thereby conflating idea and enactment and precluding improvisation. Hence, as an "embodiment of standards" of practice (Star and Ruhleder, 1996, p. 113), the influence of an IS within a field can be substantial. This is particularly the case with transformations of a field through "recurrent and reciprocal practices over time" (Orlikowski, 1996, p. 66). That transformation in the field can occur without change in practice is of essence to a field-based theory (Martin, 2003). While designed practices within a field may be viewed as constraints, they also allow for "empowering people and unleashing their creative juices" and can be "liberating" (Garvin, 1995, p. 83).

A field's effect on actants is exerted toward the perpetuation of organizational means-end values (Weber, 1978, pp. 118-137). Such values may pertain to (1) material means of production or (2) coordination of diverse activities (Weber, 1978). However, effective organizational functioning also depends on (3) defining, negotiating, and coordinating a plurality of interests among multiple stakeholders within and outside the organization. These three value domains correlate with three core organizational capabilities: capabilities that "accomplish the work of the organization", capabilities to mobilize people or behavioral processes that "infuse and shape the way work is conducted by influencing how individuals 
and groups behave", and capabilities to mobilize ideas or change processes that "alter the scale, character, and identity of the organization" (Garvin, 1998 , p. 41). Based on these notions of organizational capabilities, we characterize the three principal organizational fields as fields of production, coordination, and co-opetition.

Within each of these three fields, IS serve as "steering mechanisms" that supply capabilities and reify value-control (Myers and Young, 1997). Within each field, a force gradient exists that is amplified or muted, by the presence of IS (Martin, 2003), differentially constraining or enabling actants within the field. These force fields are depicted in Figure 1 and are now discussed.

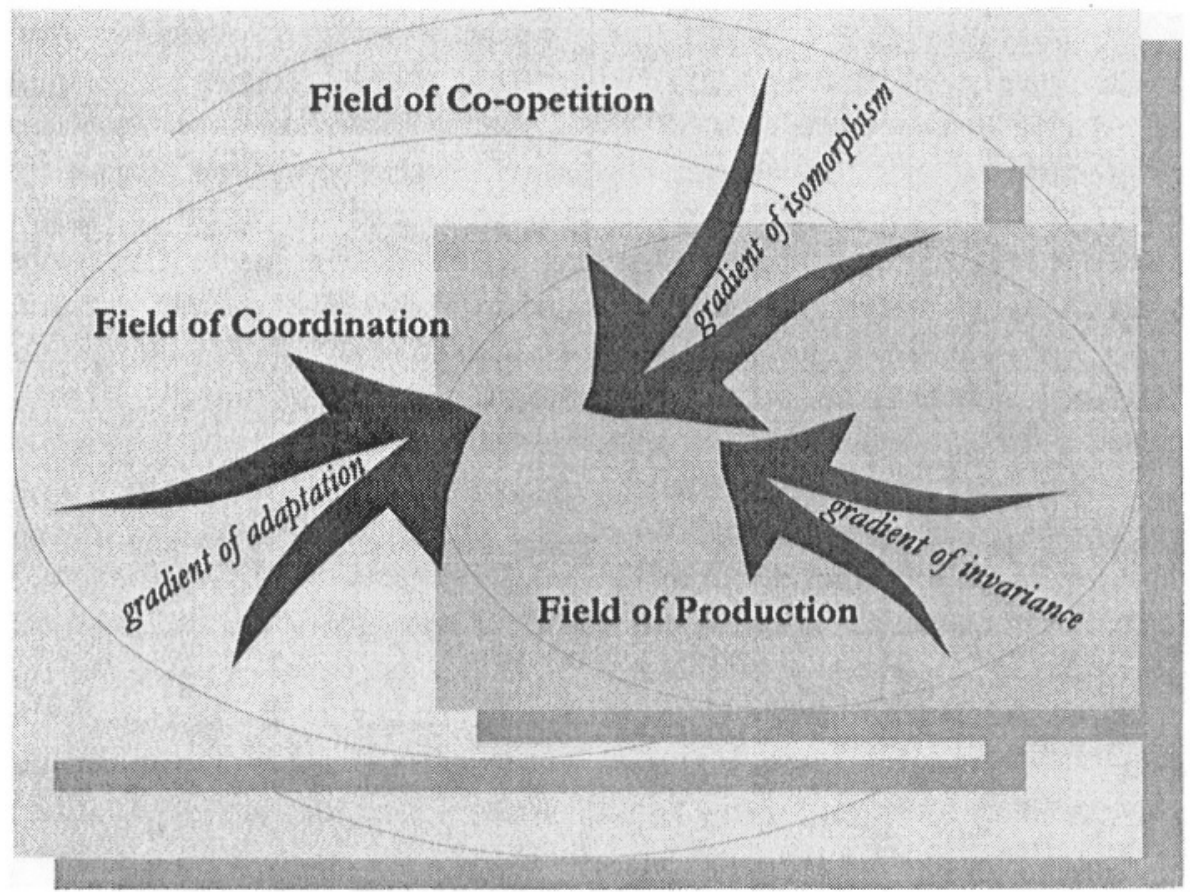

Figure 1. Organizational Force Fields Circumscribing Human and Technological Agency

\subsection{Field of Production}

The field of production is constituted by organizational units concerned with improving the organization's core competencies, i.e., the core production capabilities that are fundamental to organizations' competitiveness (Prahalad and Hamel, 1990). Capabilities in this field entail "technological and production expertise" (Stalk, Evans, and Shulman, 1992, p. 66), specifically in the primary or core processes along a firm's value 
chain. In addition to capabilities, as noted earlier, fields are defined by their underlying values. The value orientation of production fields is invariance and efficiency in the production of products and services. This is manifest in the focus of operations management and engineering disciplines on quality control and process planning and scheduling. The gradient of forces toward efficiency and invariance within this field weakens as one moves away from the firm's core value processes. This is visible in notations that experimentation via skunk works takes place at the peripheries of organizations and is precluded at the organization's core (Ciborra, 1993) as is visible with firms' experimentation with eBusiness applications (Willcocks and Plant, 2001). While core capabilities promote such experimental skunkworks at organizations' peripheries, they are not tainted by the peripheral experimentation (Meyer and Utterback, 1993).

Given the field's underlying values of invariance and efficiency, IS implemented within this field are typically oriented toward the automation of tasks within a process (Schein, 1992). Automation can eliminate jobs entirely and the efficiency and reliability of production IS are unquestionable (Gill, 1995a). In addition to themselves assuming invariant agency in production fields, IS agents also foster invariance in task performance by human agents (Gill, 1995b). In such situations, we note the power of IS agents to induce field forces upon human agents in the field.

The agency of production IS can also modify the capability requirements of human agents. Automation has been found to reduce manual and cognitive skill requirements in production tasks (Kelley, 1990; Orlikowski, 1993). However, strategic agency by human agents may enable them to circumvent or resist the forces induced by IS and their consequent capability modifications to the field. Strategic agency may even permit human agents to leverage the IS agency to increase their power, as is evinced in the conversion of blue-collar production jobs into white-collar programming jobs following automation, particularly in larger organizations with more specialized division of labor (Kelley, 1990). Automation has also been found to reduce the ranks of middle managers too, when their "structured and standardized roles facilitate top managers' efforts to substitute IT for middle managers"; in contrast, in organizations where they play unstructured roles, middle managers have been able to leverage IT to "enlarge their ranks" (Pinsonneault and Kraemer, 1993, p. 288). The distribution of power subsequently changes from a seniority basis and negotiated by collective bargaining to vestment with the bureaucracy (Kelley, 1990). 


\subsection{Field of Coordination}

Coordination refers to "a pattern of decision-making and communication among a set of actors who perform tasks in order to achieve goals" (Malone, 1987, p. 1319). The value underlying this field is adaptiveness, which enables synchronized action despite organizational and environmental variations. The field of coordination is constituted by organizational units and is concerned with their "ability to integrate, build, and reconfigure internal and external competences to address rapidly changing environments" (Teece et al., 1997, p. 516). While the value underlying this field is adaptability, capabilities from the production arena, specifically those enabling organizational units to meet and exceed organizational goals, mitigate units' position in this field. Units directly focused on executing the capabilities required to deliver on organizational goals occupy more peripheral positions in the field of coordination and are therefore less constrained by the forces of adaptation characteristic of this field. Adaptation entails managing resource allocations (Crowston, 1997), information flows (Terwiesch, Loch, and Meyer, 2002), and the media through which the first two are accomplished (Adler, 1995).

In coordination fields, IS serve as connectivity agents - transmitting information about interdependent actants and facilitating common interpretations of work tasks and resources, e.g., through negotiating acceptable results, use of resources, managing conflict (Crowston, 1997). This technological agency produces adaptability in fields of coordination by making global information available locally, and thus permitting centralized or decentralized decision-making as required by the situation (Malone, 1997). In this field, communication technologies have been observed to collaborate with human actors in the definition of communication genres: While human agents in authority positions deliberately instituted communication practices around a communication technology, the passive agency of the technology in its forum management capabilities engendered contradictory agency in the appropriation and constitution of genres by human agents occupying lower positions within the field (Yates, Orlikowski, and Okamura, 1995). In this example, we note the mutation of the structure of field positions following the technology implementation. IS have also evinced strong agency in the field of coordination, relative to human agents, resulting in the de-integration, i.e., modularization, and downsizing of organizations (Brynjolfsson, Malone, Gurbaxani, and Kambil, 1994). IS may also be co-opted by human agents to heighten their position in the field of coordination by improving their ability to enable organizational adaptation or by reifying valued production capabilities, which can then relieve them from forces of adaptation. 


\subsection{Field of Co-opetition}

The field of co-opetition is constituted by organizations' customers, suppliers, competitors, and complementers, i.e., those who increase the value of the organization's products and services. There is a fundamental duality underlying organizations' relationships with these constituencies: "Whereas creating value is an inherently cooperative process, capturing value is inherently competitive" (Brandenburger and Nalebuff, 1996, p. vii). Co-opetition refers to this dual process of cooperating and competing at all times.

The "product" of the co-opetition field is organizational identity. In the process of cooperating and competing, organizations establish their affinities and distinctions in their social space, thus defining their identity (Tajfel and Turner, 1986). Identity may also be viewed as a platform - a collection of "organizational mechanisms and forms" and the "collective, cognitive engine" that facilitate activities organizations' relationships with their coopetitors (Ciborra, 1996, p. 104). This identity is produced in practices across organizational boundaries, and in response to environmental conditions: "Any identity comes out of diametrically competing energies", through negotiations among those within a competitive space (White, 1992, p. 7). The production of identity is not unconstrained. Rather, the field of co-opetition makes available a portfolio of identities from which an organization can select (Ruef, 2000).

An organization's identity informs its goals and values, thereby constraining and enabling its choices (Albert and Whetten, 1985). Effective identity renewal is key to organizational success, even survival. Too stable an identity compromises preparedness for and responsiveness to environmental changes (Gioia, Schultz, and Corley, 2000). In contrast, 'adaptive instability' is beneficial because it permits responsive to changing environments (Gioia, Schultz, and Corley). However, identity change can be costly to manage and can damage self-esteem and is therefore often resisted (Brown and Starkey, 2000). Identities may also be pluralistic and such pluralism increases an organization's requisite variety and enhances learning and creativity and future strategic value, i.e., strategic agility (Pratt and Foreman, 2000).

In attempting to create niches that are competitive within the interorganizational field, organizations also strive for a distinctive identity (Bourdieu and Wacquant, 1992). While adaptive instability, pluralism, and distinctiveness are hallmarks of identity renewal, they can also be dysfunctional. The efficacy of pluralistic identities is also determined by how component identities inter-relate (Pratt and Foreman, 2000), and the organization's possession of "meta-identity" that is recognized by all 
constituents: "Lack of a shared identity creates dissonance and makes collective action and collective sensemaking impossible" (Brown and Starkey, 2000, p. 113). Similarly, identity continuity over time is critical as a lack of a unifying storyline creates ontological insecurity, which impinges on organizations' risk-taking (Giddens, 1991). "When major change is required, a wise way to proceed in motivating people to accept the necessity of change is to demonstrate how at least some elements of the past are valued and will be preserved" (Brown and Starkey, 2000, p. 113). Thus, successful renewal necessitates not only the repositioning of the organization so as to be distinctive, but also the maintenance of a central and continuous story line. In this sense, the tension between compliance and creation is most visible in this field (Ghoshal and Bartlett, 1995).

Renewal is a function of a specific type of organizational competence "effective identification and linking of technological options and market opportunities, and for identifying the strengths and weaknesses of existing resources relative to the requirements of a new product or process" (Dosi et al., 2002, p. 6). The capability requirement within this field is therefore boundary-spanning. We distinguish boundary-spanning from brokering, which simply entails acquiring and transferring information about opportunities and who can benefit from them. In contrast, boundaryspanning capabilities entail learning, reconfiguration, and transformation (Teece et al., 1997). It requires developing the richness of the information used in formulating strategic intent, budget objectives, and corporate policy, as well as reconciliation of disparate perspectives (Ghoshal and Bartlett, 1995). It necessitates not just the identification of significant actants, but also the elicitation of cooperation from actants with competing interests. It implies awareness, even prescience, of environmental conditions and coopting of multiple agents and indigenous and external competencies "to handle change by transforming old capabilities into new ones" (Dosi et al., 2002 , p. 7) and the ability to integrate and reconcile disparate perspectives over time and across multiple stakeholders. It requires imagination. While individual imaginations enable individuals' strategic positioning of themselves within a field, the space of this field is a corporate imagination. Within this field, organizations "unleash corporate imagination, identify and explore new competitive space, and consolidate control over emerging market opportunities" (Hamel and Prahalad, 1991, p. 82). A corporate imagination necessitates "escaping the tyranny of served markets; searching for innovative product concepts; overturning traditional assumptions about price/performance relationships; and leading customers rather than simply following them" (Hamel and Prahalad, 1991, p. 83).

The forces underlying the field of co-opetition are those of isomorphism (Martin, 2003; DiMaggio and Powell, 1983). While a distinctive identity 
may be a desirable response to an organization's contingencies, isomorphic forces differentially constrain such distinctiveness, depending on the organization's position in its organizational field. This is visible in research findings on the differential benefits that accrue to early versus late technology adopters within organizational fields. Research in the manufacturing and financial sectors has demonstrated that investments in innovative IT, i.e., the first use of a particular technology within a given industry or the deployment of technology towards development of new products, services or standards, yielded firm value increments that were not available for investments in non-innovative IT (Dos Santos, Peffers, and Mauer, 1993). Banks that first adopted ATMs were able to leverage the technology toward increased market share and sustained income gains, but this advantage was not available to later adopters of ATMs (Dos Santos and Peffers, 1995). Early adopters are then able to customize the innovations they adopt to the specific needs of their organizations, thereby improving their operations; in contrast, late adopters are precluded from such customization and their technological adoptions are instead circumscribed by the implementation patterns of early adopters, thereby providing them with none of the efficiency advantages that accrue to early adopters (Westphal, Gulati, and Shortell, 1997).

While first mover advantages may accrue to early adopters, collaboration among later-adopting competitors may generate network externalities in excess of the gains by initial adopters. Recognition of such network externalities prompted Citibank, the first-mover with ATM technology, to ultimately join the network of banks after initially refusing to do so (Brandenburger and Nalebuff, 1996). Thus, we see evidence of the forces within the co-opetition field constraining the implementation and benefits of IT in the fields of production and coordination. Prowess in the fields of production and coordination facilitate early adoption (Meyer and Utterback, 1993). Again, we see the intersection of field forces in the extent to which agents are constrained or are freed from constraint.

In the field of co-opetition, technology serves as an agent of equal, often greater, potency to/than human agents in the re-production of isomorphic field forces. This is effected via technological standards, e.g., EDI, XML, and by de facto industry practices enabled through technology, e.g., SAP within vertical industries. While horizontal standards permit compatibility and interoperability, vertical standards facilitate integration and coordination (Markus, Steinfield, and Wigand, 2003). In the adoption of horizontal or platform standards, human and technological agents reciprocally constrain future choices and interoperability (Dedrick and West, 2003). 


\section{IMPLICATIONS FOR IS INNOVATION}

This paper outlined organizational fields, within which IS possesses an agency equal to that of human actors. The articulated field theory, though only partially developed at this point, possesses a robustness absent in earlier conceptualizations of the role of IS in organizations. This is evident in our examination of the limitations of prior IS conceptualizations noted earlier. We now re-examine these limitations, and our proposed field theoretic solution, within the context of IT adoption and implementation.

First, as with human actors, IS may assume agency in one or more organizational fields, thereby generating and accounting for interdependencies among the fields and among IS within and across fields. In fact, an adopted IS is likely to manifest varying levels of functionality across all three fields. For example, a web portal focused on enabling an inter-organizational supply chain simultaneously automates procurement transactions, defines communication genres through which the conversations required for inter-firm coordination occur, and puts organizational identities into play in re-structuring supply chain relationships. Thus, viewing an IS as simultaneously constituted within fields of production, coordination, and coopetition emphasizes that all IS are multivalent in their organizational influences.

Such an observation has implications for IS adoption and implementation in that the logic driving the introduction of an IS lies within each of these three fields. Innovation champions must therefore understand the facilitating and inhibiting pressures at work within each field. They should ascertain which field has precedence at the introduction and during the innovation's long-run sustenance as an active, morphing agent within the organization. Such an understanding would enable champions to anticipate the constraints on human agency within each field. Additionally, while the human actants involved with an IS implementation initiative are influenced by these three fields, the organizational 'life space' of each individual, e.g., their functional membership, will differentiate the operant force fields. For example, while production invariance might drive a technologist to seek to increase the leveragability of an IS across the entire organization, to adopting managers, forces of production invariance may necessitate a more local effort, specifically increasing the productivity of their work processes.

Second, the complex relationships both formed and affected by an IS within organizations is reflected in recognition that the focal IS becomes just one actor among many, all of whom compete and collude with each other, and among whom contests are played out. Just as the agency of IS can constrain and facilitate human actors' development and use of their capabilities, human actors constrain and facilitate the nature and deployment 
of an IS' capabilities and each other's use of it. Such complex effects produce and are reproduced by path-dependent, episodic interactions amongst actants, thus shaping the socio-technical relationships that characterize organizations.

Here again, the implications for IS adoption and implementation are profound. Any newly introduced technology agent replaces, substitute for, augments and/or serves as a catalyst for other technology as well as human agents, each of which is influenced by operant force fields and, over time, contributes to the inherent nature of these operant force fields. Those responsible for the implementation of a new technology agent must not only recognize the salience of this network of affected/affecting agents, but must interpret their collective ramifications through filters that reflect the relative and shifting influence of the three force fields.

Finally, understanding a focal IS' evolution over time requires accounting for both (1) the interdependencies that exist among a focal IS and the other actors within an organization and (2) the interactions that parallel these interdependencies. Most important, recognizing fields of production, coordination, and co-opetition will facilitate the surfacing and examination of the focal IS' interactions with other social and artifactual actants as they play out contests across fields, and the development and deployment trajectories of the focal IS based on those interactions. Thus, while an organization's implementation of a new IS might initially be largely influenced by one force field (e.g., coordination), the trajectory of its evolution may be more heavily influenced by another force field (e.g., coopetition). For example, a web services architecture might initially be viewed as a mechanism for enterprise application integration, but then be seen as a core enabler of inter-organizational process integration. The resultant dynamics of project sponsorship, funding, leadership and membership are likely to shift dramatically as a reflection of the capital and values inherent in the operant force fields at a given point in time and space.

\section{CONCLUSION}

This paper provides a basis for studying unexplored or under-explored research domains regarding the introduction, evolution, and organizational impacts of IS. While work by researchers such as Orlikowski (2000) hints at the intersection of organizational fields via IS, there has been little explicit attention to this in IS research. Field theory not only offers a rich palette with which to outline the complexities that arise when technologies are introduced into intersecting fields, but also allows for accounts of endogenous change, i.e., that isn't externally driven but rather emerges via 
struggles within the organizational space (Bourdieu and Wacquant, 1992) that are both episodic and continuous (Martin, 2003). It thus promises to enable researchers interested in studying IS innovation to account for both planned and emergent interventions that constitute an IS implementation initiative as human agents grapple with and apply the new technology within the complex and constantly evolving network of organizational routines and practices.

These ideas also have methodological implications for IS innovation research. While prior IS innovation research has considered the individual, group, business unit, technology, or practice as a unit of analysis, this paper highlights an alternate unit - the field. Field theorists have offered the following guidance for the empirical study of fields: (1) analysis of positions occupied by actants within the field, (2) the structure of the field, and (3) genesis (history) of actants' embodied (and institutionalized) capital (Bourdieu, 1988, 1983). While ideas regarding the agency of IS in organizational fields have surfaced in IS research, we hope that our formalization and extension of these ideas invites further conceptualization and novel empirical approaches to the study of IS phenomena.

\section{REFERENCES}

Adler, P. (1995) "Interdepartmental Interdependence and Coordination: The Case of the Design/Manufacturing Interface." Organization Science, 6(2), 147-167.

Albert, S. and D.A. Whetten (1985) "Organizational Identity." In L.L. Cummings and B.M. Staw (eds.), Research in Organizational Behavior, 7, 263-295, Greenwich, CT: JAI Press.

Bloomfield, B.P. and T. Vurdubakis (1994) "Re-presenting Technology: IT Consultancy Reports as Textual Reality Constructions." Sociology, 28(2), 455-477.

Boltanski, L. and L. Thevenot (1987) "Judgment in a Multi-Natured Universe: The Problem of Agreement in a Complex Society." Symposium on Political Communication: Foundations and New Approaches, Paris, May 14-15.

Bourdieu, P. (1980) The Logic of Practice. Stanford, CA: Stanford University Press.

Bourdieu, P. (1983) "The Forms of Capital." In J.G. Richardson (ed.) Handbook of Theory and Research for the Sociology of Education, NY: Greenwood Press, 241-258.

Bourdieu, P. (1984) Distinction: A Social Critique of the Judgment of Taste. Cambridge, MA: Harvard University Press.

Bourdieu, P. (1988) "Flaubert's Point of View." Critical Inquiry, 14, 539-562.

Bourdieu, P. and L.J.D. Wacquant (1992) An Invitation to Reflexive Sociology. Chicago, IL: The University of Chicago Press.

Brandenburger, A.M. and B.J. Nalebuff (1996) "Co-opetition.” New York, NY: Currency Doubleday.

Brown, A.D. and K. Starkey, 2000 "Organizational Identity and Learning: A Psychodynamic Perspective." Academy of Management Review, 25(1), 102-120.

Brynjolfsson, E., T.W. Malone, V. Gurbaxani, and A. Kambil (1994) "Does Information Technology Lead to Smaller Firms?” Management Science, 40(12), 1628-1644. 
Churchman, C.W. (1971) The Design of Inquiring Systems: Basic Concepts of Systems and Organization. New York, NY: Basic Books, Inc.

Ciborra, C.U. (1996) "The Platform Organization: Recombining Strategies, Structures, and Surprises." Organization Science, 7(2), 103-118.

Ciborra, C.U. (1993) Teams, Markets, and Systems: Business Innovation and Information Technology, Cambridge University Press.

Crowston, K. (1997) "A Coordination Theory Approach to Organizational Process Design." Organization Science, 157-175.

Dedrick, J. and J. West (2003) "Why Firms Adopt Platform Standards: A Grounded Theory of Open Source Platforms." MISQ Special Issue Workshop on Standards, WA: Seattle.

DeSanctis, G. and M.S. Poole (1994) "Capturing the Complexity in Advanced Technology Use: Adaptive Structuration Theory.” Organization Science, 5(2), 121-147.

DiMaggio, P.J. and W.W. Powell (1983) "The Iron Cage Revisited: Institutional Isomorphism and Collective Rationality in Organizational Fields." American Sociological Review, 48, 147-160.

Dosi, G., R.R. Nelson, and S.G. Winter (2002) The Nature and Dynamics of Organizational Capabilities. Oxford University Press.

Dos Santos, B.L. and K. Peffers (1995) "Rewards to Investors in Innovative Information Technology Applications: First Movers and Early Followers in ATMs." Organization Science, 6(3), 241-259.

Dos Santos, B.L., K. Peffers, and D.C. Mauer (1993) "The Impact of Information Technology Investment Announcements on the Market Value of the Firm." Information Systems Research, 4(1), 1-23.

Feldman, M.S. and B. Pentland (2003) "Reconceptualizing Organizational Routines as a Source of Flexibility and Change." Administrative Science Quarterly, 48(1), 94-118.

Ferguson, P.P. (1998) "A Cultural Field in the Making: Gastronomy in $1 \mathbf{9}^{\text {th }}$-Century France." American Journal of Sociology, 104(3), 597-641.

Garvin, D.A. (1995) "Leveraging Processes for Strategic Advantage." Harvard Business Review, 73(5), 77-90.

Garvin, D.A. (1998) "The Processes of Organization and Management." Sloan Management Review, 33-50.

Ghoshal, S. and C.A. Bartlett (1995) "Changing the Role of Top Management: Beyond Structure to Processes." Harvard Business Review, January-February, 86-96.

Giddens, A. (1991) Modernity and Self-Identity: Self and Society in the Late Modern Age. Stanford, CA: Stanford University Press.

Gill, T.G. (1996) "Expert Systems Usage: Task Change and Intrinsic Motivation." MIS Quarterly, 20(3). 301-330.

Gill, T.G. (1995a) "High-Tech Hidebound: Case Studies of Information Technologies that Inhibited Organizational Learning." Accounting, Management, and Information Technology, 5(1), 41-60.

Gill, T.G. (1995b) "Early Expert Systems: Where are They Now?" MIS Quarterly, 19(1), 5181.

Gioia, D.A., M. Schultz, and K.G. Corley (2000) "Organizational Identity, Image, and Adaptive Instability." Academy of Management Review, 25(1), 63-81.

Hamel, G. and C.K. Prahalad (1991) "Corporate Imagination and Expeditionary Marketing." Harvard Business Review, 69(4), 81-92.

Kelley, M.R. (1990) "New Process Technology, Job Design, and Work Organization: A Contingency Model." American Sociological Review, 55(2), 191-208. 
Lamb, R. and R. Kling (2003) "Reconceptualizing Users as Social Actors in Information Systems Research." MIS Quarterly, 27(2), 197-236.

Law, J. and J. Hassard (1999) Actor-Network Theory and After. Blackwell Publishers.

Lewin, K. (1951) Field Theory in Social Science, New York, NY: Harper and Brothers.

Malone, T. W. (1987) "Modeling Coordination in Organizations and Markets." Management Science, 33(10), 1317-1331.

Malone, T.W. (1997) "Is Empowerment Just a Fad? Control, Decision-making, and IT." Sloan Management Review, 38(2), 23-35.

Markus, M.L., C.W. Steinfield, and R.T Wigand (2003) "The Evolution of Vertical IS Standards: Electronic Interchange Standards in the U.S. Home Mortgage Industry.” MISQ Special Issue Workshop on Standards, WA: Seattle.

Markus, M.L. and J. Pfeffer (1983) "Power and the Design and Implementation of Accounting and Control Systems." Accounting, Organizations, and Society, 8(2), 205218.

Martin, J.L. (2003) "What is Field Theory?" American Journal of Sociology, 109(1), 1-49.

Meyer, M.H. and J.M. Utterback (1993) "The Product Family and the Dynamics of Core Capability." Sloan Management Review, 34(3), 29-47.

Myers, M.D. and L.W. Young (1997) "Hidden Agendas, Power, and Managerial Assumptions in Information Systems Development: An Ethnographic Study." Information Technology and People, 10(3), 224-.

Orlikowski, W.J. (2000) "Using Technology and Constituting Structures: A Practice Lens for Studying Technology in Organizations." Organization Science, 11(4), 404-428.

Orlikowski, W.J. (1996) "Improvising Organizational Transformation Over Time: A Situated Change Perspective." Information Systems Research, 7(1), 63-92.

Orlikowski, W.J. (1993) "CASE Tools as Organizational Change: Investigating Incremental and Radical Changes in Systems Development." MIS Quarterly, 17(3), 309-340.

Prahalad, C.K. and G. Hamel (1990) "The Core Competence of the Corporation." Harvard Business Review, 68(3), 79-91.

Pinsonneault, A. and K.L Kraemer (1993) "The Impact of Information Technology on Middle Managers." MIS Quarterly, 17(3), 271-292.

Pratt, M.G. and P.O. Foreman (2000) "Classifying Managerial Responses to Multiple Organizational Identities." Academy of Management Review, 25(1), 18-42.

de Rivera, J. (1976) Field Theory as Human-Science. New York, NY: Gardner Press, Inc.

Ruef, M. (2000) "The Emergence of Organizational Forms: A Community Ecology Approach." The American Journal of Sociology, 106(3), 658-714.

Schein, E.H. (1992) "The Role of the CEO in the Management of Change: The Case of Information Technology." In T.A. Kochan and U. Useem (eds.), Transforming Organizations. Oxford, Oxford University Press, 80-96.

Stalk, G., P. Evans, and L.E. Shulman (1992) "Competing on Capabilities: The New Rules of Corporate Strategy." Harvard Business Review, 70(2), 57-69.

Star, S.L. and K. Ruhleder (1996) "Steps Toward an Ecology of Infrastructure: Design and Access for Large Information Spaces.” Information Systems Research, 7(1), 111-134.

Stewart, T.A. (1999) Intellectual Capital: The New Wealth of Organizations. New York, NY: Currency-Doubleday.

Tajel, H. and J.C. Turner (1986) "The Social Identity Thoery of Intergroup Behavior." In S. Worschel and W.G. Austin (eds.) Psychology of Intergroup Relations, Chicago, IL: Nelson-Hall.

Teece, D.J., G. Pisano, and A. Shuen (1997) "Dynamic Capabilities and Strategic Management." Strategic Management Journal, 18, 509-533. 
Terwiesch, C., C.H. Loch, and A. Meyer (2002) "Exchanging Preliminary Information in Concurrent Engineering: Alternative Coordination Strategies." Organization Science, 13(4), 402-422.

Tornatzky, L.G. and M. Fleischer (1990) The Processes of Technological Innovation. Lexington, MA: Lexington Books.

Weber, M. (1978) Economy and Society. Berkeley, CA: University of California Press.

Weick, K.E. (1995) Sensemaking in Organizations. Thousand Oaks, CA: Sage Publications.

Westphal, J.D., R. Gulati, and S.M. Shortell (1997) "Customization or Conformity? An

Institutional and Network Perspective on the Content and Consequences of TQM Adoption." Administrative Science Quarterly, 42, 366-394.

White, H.C. (1992) Identity and Control: A Structural Theory of Social Action. Princeton, NJ: Princeton Books.

Willcocks, L.P. and R. Plant (2001) "Pathways to e-Business Leadership: Getting from Bricks to Clicks." Sloan Management Review, 42(3), 50-59.

Woodward, J. (1994/1965) Industrial Organization: Theory and Practice $\left(2^{\text {nd }}\right.$ edition). New York, NY: Oxford University Press.

Yates, J., W.J. Orlikowski, and K. Okamura (1995) "Constituting Genre Repertoires: Deliberate and Emergent Patterns of Electronic Media Use." Academy of Management Proceedings, 353-357.

Zimmerman, M.E. (1990) Heidegger's Confrontation with Modernity, Bloomington, IN: Indiana University Press. 